\title{
Outcome of the Norwood operation in patients with hypoplastic left heart syndrome: A 12-year single-center survey
}

\author{
Anke Katharina Furck, MD, ${ }^{\mathrm{a}}$ Anselm Uebing, MD, ${ }^{\mathrm{a}}$ Jan Hinnerk Hansen, ${ }^{\mathrm{a}}$ Jens Scheewe, MD, \\ Olaf Jung, MD, ${ }^{\mathrm{a}}$ Gunther Fischer, MD, ${ }^{\mathrm{a}}$ Carsten Rickers, MD, ${ }^{\mathrm{a}}$ Tim Holland-Letz, MSc, ${ }^{\mathrm{c}}$ \\ and Hans-Heiner Kramer, MD ${ }^{\mathrm{a}}$
}

Objective: Recent advances in perioperative care have led to a decrease in mortality of children with hypoplastic left heart syndrome undergoing the Norwood operation. This study aimed to evaluate the outcome of the Norwood operation in a single center over 12 years and to identify clinical and anatomic risk factors for adverse early and longer term outcome.

Methods: Full data on all 157 patients treated between 1996 and 2007 were analyzed.

Results: Thirty-day mortality of the Norwood operation decreased from $21 \%$ in the first 3 years to $2.5 \%$ in the last 3 years. The estimated exponentially weighted moving average of early mortality after 157 Norwood operations was $2.3 \%$. Risk factors were an aberrant right subclavian artery, the use and duration of circulatory arrest, and the duration of total support time. The anatomic subgroup mitral stenosis/aortic atresia and female gender tended to show an increased early mortality. In the group of patients who required postoperative cardiopulmonary resuscitation, the ascending aorta was significantly smaller than in the remainder $(3.03 \pm 1.05$ vs $3.63 \pm 1.41$ $\mathrm{mm}$ ). Interstage mortality was $15 \%$ until the initiation of a home surveillance program in 2005 , which has zeroed it so far. It was significantly higher in the mitral stenosis/aortic atresia subgroup and tended to be higher in patients who required cardiopulmonary resuscitation after the Norwood operation. The best actuarial survival was observed in the mitral atresia/aortic atresia subgroup.

Conclusion: The Norwood operation can now be performed with low mortality. Patients with mitral stenosis/aortic atresia still constitute the most challenging subgroup.(J Thorac Cardiovasc Surg 2010;139:359-65)

\section{Earn CME credits at}

http://cme.ctsnetjournals.org

Two decades ago, treatment options of hypoplastic left heart syndrome (HLHS) were limited owing to high mortality rates. ${ }^{1,2}$ Therefore, in most centers patients were advised to either terminate pregnancy or provide compassionate care after birth. Since then, mortality rates have declined constantly owing to improvements in surgical technique and perioperative treatment. ${ }^{3,4}$ However, the Norwood operation is still considered a high-risk procedure and interstage mortality from the Norwood operation to the subsequent hemi-Fontan operation is still a matter of concern, with mortality rates in the range of $11 \%$ to $15 \%{ }^{3,5,6}$

\footnotetext{
From the Departments of Pediatric Cardiology ${ }^{\mathrm{a}}$ and Cardiovascular Surgery, ${ }^{\mathrm{b}}$ University Hospital of Schleswig-Holstein, Campus Kiel, Kiel, Germany; and the Department of Medical Informatics, Biometry and Epidemiology, ${ }^{\mathrm{c}}$ Bochum, Germany. Disclosures: None.

Received for publication Dec 16, 2008; revisions received June 23, 2009; accepted for publication July 23, 2009; available ahead of print Nov 2, 2009.

Address for reprints: Anke Katharina Furck, MD, Department Pediatric Cardiology, University Hospital of Schleswig-Holstein, Campus Kiel, Arnold-Heller Strasse 3, House 9, 24105 Kiel, Germany (E-mail: akfurck@aol.com). $0022-5223 / \$ 36.00$

Copyright (c) 2010 by The American Association for Thoracic Surgery doi:10.1016/j.jtcvs.2009.07.063
}

The aim of our study was to analyze the outcome of patients with HLHS who received their Norwood operation between 1996 and the end of 2007 and to identify clinical and anatomic risk factors for adverse early and longer term outcome.

\section{PATIENTS AND METHODS}

Our study population consisted of 157 patients with HLHS as defined by the Nomenclature Working Group of the International Society of Nomenclature of Paediatric and Congenital Heart Disease, ${ }^{7}$ who were treated in our institution between January 1996 and December 2007.

We reviewed our HLHS database for data on anatomy, extracardiac lesions, surgical and perioperative treatment, perioperative complications, and death. All parents gave their informed consent to the anonymized analysis of the data and the study was approved by the local research ethics committee.

\section{Anatomic Data}

On the basis of echocardiography performed before the Norwood operation by two experienced investigators, all patients were assigned to distinct anatomic subgroups adhering to a classification system proposed by the International Society of Nomenclature of Paediatric and Congenital Heart Disease and previously used by Tchervenkov, ${ }^{7}$ Jacobs, ${ }^{8}$ and their coworkers. These subgroups were mitral atresia/aortic atresia (MA/AA), mitral stenosis/aortic stenosis (MS/AS), mitral stenosis/aortic atresia (MS/AA), and mitral atresia/aortic stenosis (MA/AS). Additionally, the size of the ascending aorta was determined and additive anatomic findings evaluated. The distinction of valve stenosis and atresia was based on the presence or absence of opening and flow across the valve. The diagnosis of a restrictive atrial septum was made on the basis 


$$
\begin{aligned}
& \text { Abbreviations and Acronyms } \\
& \text { ASCP }=\text { antegrade selective cerebral perfusion } \\
& \text { CI }=\text { confidence interval } \\
& \text { DHCA }=\text { deep hypothermic circulatory arrest } \\
& \text { HLHS }=\text { hypoplastic left heart syndrome } \\
& \text { MA/AA }=\text { mitral atresia/aortic atresia } \\
& \text { MA/AS }=\text { mitral atresia/aortic stenosis } \\
& \text { MS/AA }=\text { mitral stenosis/aortic atresia } \\
& \text { MS/AS }=\text { mitral stenosis/aortic stenosis } \\
& \text { OR }=\text { odds ratio }
\end{aligned}
$$

of echocardiography in conjunction with clinical data such as $\mathrm{PaO}_{2}$ below 35 $\mathrm{mm} \mathrm{Hg}$ and/or pulmonary venous congestion detected on radiography.

\section{Preoperative Management}

Preoperatively, all children were treated according to a standardized regimen as previously described ${ }^{9}$ and consisting of strict afterload reduction with sodium nitroprusside or phentolamine, low-dose prostaglandin $E_{1}$, furosemide, enteral feeding, and avoidance of mechanical ventilation or inotropic support. If inotropic support was mandatory or commenced externally in children with cardiogenic shock, it was terminated as soon as possible.

\section{Surgical Management}

The majority of all Norwood operations were performed by a single surgeon $(n=148 / 157)$. In the period from 1996 until January 2000, deep hypothermic circulatory arrest (DHCA) was used $(n=39)$. Since then, all patients $(n=118)$ were operated on with low-flow antegrade selective cerebral perfusion (ASCP) during the reconstruction of the aortic arch so that DHCA could be avoided. Until September 1999, the aortic arch was augmented with pulmonary homograft material. From October 1999 onward, bovine pericardium was used. Pulmonary perfusion was achieved with a modified Blalock-Taussig shunt, which was placed between the innominate artery and the bifurcation of the pulmonary arteries, a central aortopulmonary shunt, or a right ventricular-pulmonary artery conduit (Sano shunt), which was inserted into the right side of the aorta.

The $\mathrm{pH}$-stat method was used for cooling to a temperature of $18^{\circ} \mathrm{C}$ and continued during bypass with an intermittent low-flow strategy. The patient was rewarmed with the $\alpha$-stat method. Since January 2000, hemofiltration has been routinely used.

\section{Postoperative Management}

Postoperatively, all patients were continued on afterload reduction therapy, with either phentolamine or sodium nitroprusside. Inotropic support was achieved with epinephrine and enoximone. For anticoagulation $3 \mathrm{mg} /$ $\mathrm{kg}$ acetylsalicylic acid was routinely given. In October 2005 we introduced a home surveillance program $(\mathrm{n}=29)$ as described by Ghanayem and associates ${ }^{10}$ to reduce interstage mortality.

After the Norwood operation, patients were discharged from the hospital if they could be fed orally without a gastric tube, were thriving, and had an oxygen saturation greater than $75 \%$.

The indication to perform the hemi-Fontan operation as the second step of palliation was based on multiple clinical variables taking into account the patient's oxygen saturation $(<80 \%)$ and weight $(>5 \mathrm{~kg})$, potential signs of uncontrollable heart failure, and right ventricular function.

\section{Outcome Measures}

Thirty-day mortality was defined as death within the first 30 days of the Norwood operation regardless of whether in or out of the hospital. Death after this period and until the subsequent palliative surgery, regardless of whether in or out of the hospital, was defined as interstage mortality. Actuarial survival was calculated with the Kaplan-Meier method.

Additional adverse outcome measures were classified into neurologic complications (seizures, cerebral hemorrhage, cerebral infarct), hypoxic and hemodynamic complications (shunt occlusion, cardiac arrhythmias needing intervention, shock defined as a low cardiac output state needing pharmacologic resuscitation, bleeding leading to hemodynamic compromise and requiring immediate blood transfusion), cardiopulmonary resuscitation including chest compression, and others (liver and kidney insufficiency as previously defined, ${ }^{9}$ necrotizing enterocolitis, and sepsis diagnosed according to the criteria of the International Consensus Conference on Pediatric Sepsis). ${ }^{11}$

\section{Statistical Analysis}

Statistical analyses were performed with the statistical software package SPSS 15.0 (SPSS Inc, Chicago, Ill). Continuous variables are presented as mean \pm standard deviation or median and range as appropriate, and categorical data are given as count and percentages. Selected continuous variables were dichotomized to create categorical variables.

Categorical data were analyzed with the $\chi^{2}$ or Fisher exact test as appropriate. Continuous variables were analyzed with the Student $t$ test after testing for equality of variances with the Levene test. Nonparametric tests for two independent samples were performed with the Mann-Whitney $U$ test; for more than two samples, the Kruskal-Wallis test was applied. Cardiopulmonary support times were evaluated with univariate logistic regression. For evaluation of risk factors for 30-day and interstage mortality, variables with a value of $P \leq .1$ on univariate analysis were entered into a multivariate stepwise logistic regression analysis model. Results are presented as odd ratios (OR) with $95 \%$ confidence intervals (CI). To show variations and trends over time, we calculated 30-day mortality after the Norwood operation as exponential weighted moving average. The exponential weighted moving average method was applied by de Leval and colleagues ${ }^{12}$ in a series of arterial switch operations and used in two studies with patients who had HLHS by McGuirk and coworkers. ${ }^{5,13}$ This method emphasizes more recent results by downweighting each previous observation by $5 \%$. CIs were calculated by the method by Wilson. Survival analysis was performed by the Kaplan-Meier method, and the Breslow test (generalized Wilcoxon) was used to test equality of survival distributions on univariate analysis. Variables with a value of $P \leq 0.1$ were entered into a stepwise Cox regression analysis model. All other statistical tests were performed with a level of significance of $5 \%$.

\section{RESULTS}

Patient characteristics, including gender, prenatal diagnosis, preterm birth weight of $2.5 \mathrm{~kg}$ or less, preoperative complications and treatment, anatomic subgroups, additional cardiovascular anomalies and extracardiac anomalies, and additional operations between the Norwood and subsequent hemi-Fontan operation are shown in Table 1 . The mean diameter of the ascending aorta was $3.49 \pm 1.36 \mathrm{~mm}$. The ascending aorta was smallest in patients with MA/AA.

\section{Norwood Operation}

Details regarding the Norwood operation are displayed in Table 2. In 143 patients, pulmonary blood flow was established with a modified Blalock-Taussig shunt. In 12 patients with an aberrant right subclavian artery, a central aortopulmonary shunt was placed and 2 patients were palliated with a right ventricular-pulmonary artery conduit. In patients 
TABLE 1. Patient characteristics $(\mathbf{n}=157) *$

\begin{tabular}{|c|c|}
\hline \multicolumn{2}{|l|}{ General information } \\
\hline Female & $56(35.7)$ \\
\hline Male & $101(64.3)$ \\
\hline Premature infants & $10(6.4)$ \\
\hline$\leq 2.5 \mathrm{~kg}$ & $19(12)$ \\
\hline Prenatal diagnosis, yes & $72(45.9)$ \\
\hline \multicolumn{2}{|l|}{ Preoperative complications $\uparrow$} \\
\hline Cardiopulmonary resuscitation & $5(3.2)$ \\
\hline Cerebral complications & $6(3.8)$ \\
\hline Necrotizing enterocolitis & $10(6.4)$ \\
\hline Hepatic/renal failure & $13(8.3)$ \\
\hline Sepsis & $2(1.3)$ \\
\hline \multicolumn{2}{|l|}{ Preoperative treatment } \\
\hline Initial inotropic support & $27(17.2)$ \\
\hline Continuous inotropic support & $1(0.6)$ \\
\hline Initial mechanical ventilation & $43(27.4)$ \\
\hline Continuous mechanical ventilation & $11(7.0)$ \\
\hline Pulmonary artery banding & $6(3.8)$ \\
\hline Atrial septectomy & $2(1.3)$ \\
\hline \multicolumn{2}{|l|}{$\begin{array}{l}\text { Procedures between Norwood and hemi-Fontan } \\
\text { operations }\end{array}$} \\
\hline Revision/replacement of the modified BT shunt & $20(12.8)$ \\
\hline Rethoracotomy for uncontrollable bleeding & $4(2.6)$ \\
\hline Rethoracotomy to reduce BT shunt size & $4(2.6)$ \\
\hline Pulmonary artery banding & $1(0.6)$ \\
\hline Abdominal surgery for necrotizing enterocolitis & $2(1.3)$ \\
\hline Shunting of a hydrocephalus & $1(0.6)$ \\
\hline Fundoplication & $1(0.6)$ \\
\hline \multicolumn{2}{|l|}{ Anatomic subgroups } \\
\hline MA/AA & $70(44.6)$ \\
\hline MS/AS & $42(26.7)$ \\
\hline MS/AA & $34(21.7)$ \\
\hline MA/AS & $11(7)$ \\
\hline \multicolumn{2}{|l|}{$\begin{array}{l}\text { Native diameter of the } \\
\text { ascending aorta } \ddagger\end{array}$} \\
\hline MA/AA (mm) & $2.69 \pm 0.79$ \\
\hline MS/AS (mm) & $4.77 \pm 1.21$ \\
\hline MS/AA (mm) & $3.14 \pm 0.90$ \\
\hline MA/AS (mm) & $4.77 \pm 1.47$ \\
\hline \multicolumn{2}{|l|}{ Additional cardiovascular anomalies $\dagger$} \\
\hline Restrictive atrial septal defect & $9(5.7)$ \\
\hline Ventricular septal defect & $18(11.5)$ \\
\hline Tricuspid valve insufficiency & $16(10.2)$ \\
\hline Aberrant right subclavian artery & $13(8.3)$ \\
\hline Truncus bicaroticus & $1(0.6)$ \\
\hline Pulmonary valve anomaly & $5(3.2)$ \\
\hline Systemic venous anomaly & $13(8.3)$ \\
\hline $\begin{array}{l}\text { Total anomalous pulmonary } \\
\text { venous connection }\end{array}$ & $4(2.5)$ \\
\hline $\begin{array}{l}\text { Partial anomalous pulmonary } \\
\text { venous connection }\end{array}$ & $4(2.5)$ \\
\hline \multicolumn{2}{|l|}{ Extracardiac anomalies $\dagger$} \\
\hline Genetic anomalies & $3(1.9)$ \\
\hline Congenital hydrocephalus & $2(1.3)$ \\
\hline Renal dysplasia & $1(0.6)$ \\
\hline Intestinal malrotation/nonrotation & $3(1.9)$ \\
\hline
\end{tabular}

TABLE 1. Continued

\begin{tabular}{lc}
\hline Esophageal atresia & $1(0.6)$ \\
Laryngomalacia & $1(0.6)$ \\
Congenital hypothyroidism & $1(0.6)$ \\
Coagulation disorder & $8(5.1)$ \\
\hline$B T$, Blalock-Taussig; $M A / A A$, mitral atresia/aortic atresia; $M S / A S$, mitral stenosis/aor- \\
tic stenosis; $M S / A A$, mitral stenosis/aortic atresia; $M A / A S$, mitral atresia/aortic stenosis. \\
*Data are given with numbers and percentage in parentheses. $\dagger$ Multiple diagnoses per \\
patient are possible. $\ddagger$ Data are given as mean \pm SD. The group with MA/AA had a sig- \\
nificantly smaller ascending aorta than MS/AS, MS/AA, and MA/AS.
\end{tabular}

without ASCP, mean DHCA time was $71.1 \pm 16.6$ minutes and mean duration of cardiac ischemia was $72.9 \pm 15.3$ minutes, which was significantly lower in patients with ASCP (54.9 \pm 17.3 minutes). In the subgroup of patients operated on without ASCP, DHCA time was inversely related to the time interval from the Norwood operation to analysis of the data (follow-up time) $(r=-0.47, P<.01)$. In the entire patient cohort, cardiac ischemia time was inversely related with follow-up time $(r=-0.67, P<.001)$. Total support time did not show differences between patients with and without ASCP. The chest was left primarily open in 22 patients.

\section{Postoperative Care}

For the whole group the median duration of postoperative ventilation was 72 hours (16-1191 hours), without significant differences between anatomic subgroups. The median length of stay after the Norwood operation was 42 days (12-353 days). Fifteen patients could not be discharged before the hemi-Fontan operation.

\section{Postoperative Complications}

Postoperative complications were observed in 89 $(56.7 \%)$ patients after the Norwood operation. Their frequency did not show significant differences between the anatomic subgroups (Table 3). No patient received extracorporeal membrane oxygenator support after the Norwood operation. Evaluation of risk factors for postoperative complications showed that cardiopulmonary resuscitation tended to be more likely in patients with aortic atresia (MA/AA and MS/AA vs MS/AS and MA/AS [OR 2.42, 95\% CI 0.98-5.99]). Those patients who required a cardiopulmonary resuscitation had significantly smaller diameters of the ascending aorta $(3.03 \pm 1.05 \mathrm{vs} 3.63 \pm 1.41 \mathrm{~mm})$. The use and the duration of DHCA were significantly related to cerebral complications.

\section{Subsequent Procedures and Follow-up}

As the second step of the palliation, a hemi-Fontan operation was performed in 119 patients with 116 survivors at a median age of 4.5 months (1.2-45.7 months). Eight patients died during the interstage period before completion of the Fontan circulation. The latter was performed in 
TABLE 2. Details regarding the Norwood operation

\begin{tabular}{lc} 
& Norwood $(\mathbf{n}=\mathbf{1 5 7})$ \\
\hline Median age at operation (d) & $7(1-57)$ \\
Weight at operation $(\mathrm{kg})$ & $3.2 \pm 0.5$ \\
Shunt diameter $3 \mathrm{~mm}(\mathrm{n})$ & 56 \\
Shunt diameter $3.5 \mathrm{~mm}(\mathrm{n})$ & 78 \\
Shunt diameter $4.0 \mathrm{~mm}(\mathrm{n})$ & 21 \\
Shunt diameter $5 \mathrm{~mm}^{*}(\mathrm{n})$ & 2 \\
Index shunt size $\left(\mathrm{mm}^{2} / \mathrm{kg}\right)$ & $2.88 \pm 0.58$ \\
Bypass time (min) & $135(31-265)$ \\
Aortic crossclamp (min) & $42(0-80)$ \\
Deep hypothermic arrest (min) & $7(0-127)$ \\
Cardiac ischemia time (min) & $59.36 \pm 18.53$ \\
Total support time (min) & $152.06 \pm 31.33$ \\
\hline *Patients with right ventricular-pulmonary artery conduit.
\end{tabular}

72 patients until the end of the study period without an early death but with 2 late deaths. Three patients underwent transplantation during the study period ( 1 after the Norwood operation; 2 after the hemi-Fontan operation). Follow-up was complete for all surviving patients $(\mathrm{n}=110)$ with a median follow up period of 5.09 years (0.13-11.83 years).

The size of the Blalock-Taussig shunt affected the timing of the hemi-Fontan operation. We found an almost significant difference in the shunt index between the group of patients who were younger than or equal to the median age of 4.5 months at hemi-Fontan operation compared with those older than 4.5 months (indexed shunt size in patients aged $\leq 4.5$ months versus $>4.5$ months: $2.78 \pm 0.31$ vs $3.0 \pm$ $\left.0.8 \mathrm{~mm}^{2} / \mathrm{kg}, P=.05\right)$.

\section{Thirty-day mortality}

Thirty-day mortality was $21 \%$ in the first 3 years and $2.5 \%$ in the last 3 years. After 157 Norwood operations, the exponential weighted moving average estimated a $30-$ day mortality rate of $2.3 \%$ (Figure 1). Univariate analysis identified an aberrant right subclavian artery and the use of DHCA as significant risk factors for 30-day mortality (Table 4). In addition, duration of DHCA, cardiac ischemic time, and total support time were significantly related to 30-day mortality on univariate logistic regression analysis. A tendency toward a higher risk for death within 30 days was observed in the anatomic subgroup MS/AA (OR, 2.64; 95\% CI, 0.94-7.44) and for female gender (OR, 2.61; CI, 0.97-7.06).

On multivariate regression analysis, the lack of ASCP (OR, 4.85; 95\% CI, 1.61-14.58) and an increase in total support time (OR, $1.41 ; 95 \%$ CI, $1.16-1.72$ per 15 -minute increase) were independently associated with 30-day mortality after the Norwood operation.

\section{Interstage Mortality}

Interstage mortality was $15 \%(\mathrm{n}=11 / 106)$ and dropped to $0 \%(n=0 / 29)$ after the initiation of our home surveillance program.
TABLE 3. Complications after the Norwood operation according to anatomic subgroups*

\begin{tabular}{|c|c|c|c|c|c|}
\hline & $\begin{array}{l}\text { МА/AA } \\
(\mathbf{n}=\mathbf{7 0}) \\
\end{array}$ & $\begin{array}{c}\text { MS/AS } \\
(n=42) \\
\end{array}$ & $\begin{array}{c}\text { MS/AA } \\
(n=34) \\
\end{array}$ & $\begin{array}{l}\text { MA/AS } \\
(n=11)\end{array}$ & $\begin{array}{c}P \\
\text { value } \\
\end{array}$ \\
\hline $\begin{array}{l}\text { No. of patients } \\
\quad \text { with complications }\end{array}$ & 36 & 21 & 23 & 9 & .116 \\
\hline $\begin{array}{l}\text { Cardiopulmonary } \\
\text { resuscitation }\end{array}$ & 17 & 6 & 11 & 1 & .205 \\
\hline $\begin{array}{l}\text { Hypoxic, hemodynamic } \\
\text { complications }\end{array}$ & 30 & 13 & 12 & 4 & .651 \\
\hline Cerebral complications & 4 & 3 & 3 & 2 & .448 \\
\hline Other & 12 & 4 & 9 & 4 & .091 \\
\hline
\end{tabular}

In Table 4, the results of the univariate analysis of risk factors for interstage mortality are shown. A significantly higher risk for interstage mortality was found for the anatomic subgroup MS/AA (OR, 4.09; 95\% CI, 1.36-12.35). Patients with MA/AA showed favorable outcomes during the interstage period compared with the other subgroups. There was a relatively high risk of interstage mortality in patients who required cardiopulmonary resuscitation during the hospital course after the Norwood operation (OR, 2.93; 95\% CI, 0.90-9.53).

\section{Actuarial Survival}

Overall actuarial survival was $73.5 \%$ at 1 year and $68.4 \%$ at 5 years. Relevant differences were noticed between anatomic subgroups (Figure 2). One-year survival $(81.9 \%$ ) and 5-year survival $(76.8 \%)$ were highest for patients with MA/AA. For the other subgroups, survival was lower (MS/AS: $78.2 \%$ and $69.7 \%$; MA/AS: $63.6 \%$ and $50.9 \%$; MS/AA: $55.6 \%$ and $55.6 \%$ ).

Risk factors influencing long-term survival after a successful Norwood operation were analyzed excluding patients who died within 30 days after the Norwood operation. On univariate analysis, the anatomic subgroup significantly influenced actuarial survival. On pairwise analysis, patients with MA/AA had significantly higher survivals than patients with MS/AA. Between the remaining subgroups, no significant differences were found.

Multivariate Cox regression analysis revealed that patients with MA/AA had a lower risk for death after a successful Norwood operation compared with the MS/AA and MA/ AS subgroups. Postoperative cardiopulmonary resuscitation and an ascending aorta less than $2 \mathrm{~mm}$ also adversely affected survival after successful Norwood operation on multivariate analysis (Table 5).

\section{DISCUSSION}

Over a period of 12 years, early mortality of the Norwood operation could be reduced in our institution from $21 \%$ in 


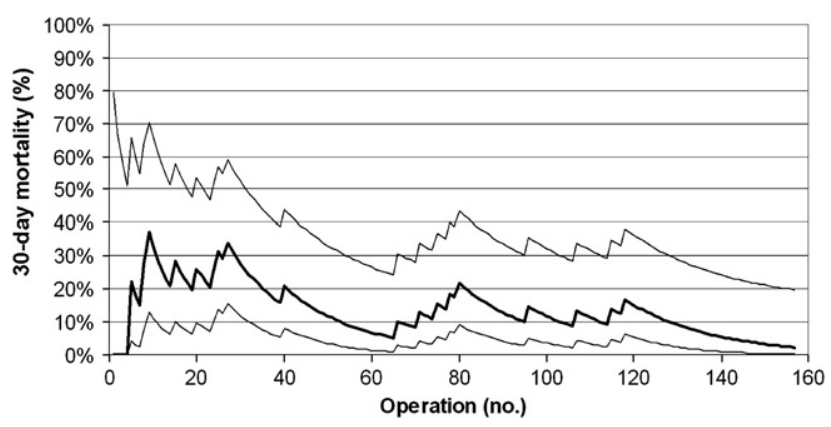

FIGURE 1. Thirty-day mortality after the Norwood operation. Exponentially weighted moving average with $95 \%$ confidence intervals.

the initial 3-year interval to $2.5 \%$ in the last 3 years. In accordance with this, the exponentially weighted early mortality decreased continuously to $2.3 \%$ at the end of the study period. A notable decrease in early mortality after the Norwood procedure has also been reported by other groups. ${ }^{3,5}$

\section{Improvement in Management}

The reasons for this achievement are certainly numerous, with an overall gain of experience during the study period being one reason. The inverse relationships between the cardiac ischemia time and DHCA time with the follow-up interval do support this conjecture. However, strict adherence to a uniform preoperative treatment strategy with avoidance of mechanical ventilation and inotropic support ${ }^{9}$ and sufficient afterload reduction have certainly substantially contributed.

Key in our postoperative management was an adequate afterload reduction. It has been shown by Tweddell and coworkers ${ }^{3}$ that a sufficient afterload reduction helps to avoid an abrupt increase in systemic vascular resistance in the postoperative course and, in conjunction with manipulating inflammatory response, accounts for the reduction in early mortality. Other centers reported that the use and duration of DHCA are significant contributors to early mortality. $3,6,14$ With the introduction of ASCP in 2000, we initially reduced and eventually avoided DHCA, hence eliminating this risk factor. The increased risk for early mortality with longer total support time described by Gaynor and colleages ${ }^{15}$ and was confirmed by our study.

\section{Anatomic Risk Factors}

The anatomy of MS/AA was associated with an increased risk for early death after the Norwood operation, a finding also reported by others. ${ }^{16-18}$ Adverse left ventricular-right ventricular interaction might contribute to this finding. Sugiyama and associates ${ }^{19}$ revealed myocardial necrosis, calcification, and fibrosis in the left ventricle of patients with MS/ AA and noticed impaired posterior wall motion of the right ventricle with compensatory hyperkinesias of the anterior wall. Additionally, endocardial fibroelastosis, endocardial thickness, and myocardial fibrosis were more pronounced in these left ventricles compared with those in the other anatomic subgroups. It can therefore be assumed, that the left ventricle in the setting of MS/AA is a functional burden to the right ventricle ("piggyback ventricle") with deleterious effects on outcome. Further research on the functional impact of the hypoplastic left ventricle on right ventricular function is clearly warranted. Additionally, coronary artery abnormalities such as coronary fistulas that were described by Vida and coworkers ${ }^{17}$ potentially affect myocardial perfusion in patients with MS/AA. As such abnormalities are sometimes difficult to visualize by echocardiography, coronary anomalies were not included in the retrospective risk factor analysis presented here.

In accordance with Ishino and coworkers, ${ }^{14}$ we found the presence of an aberrant right subclavian artery to be a risk factor for 30-day mortality. Patients with this anomaly out of necessity received a central aortopulmonary shunt from the ascending aorta to the bifurcation of the pulmonary arteries. The proximity of this shunt to the origin of the coronary system certainly contributed to an impaired coronary perfusion by runoff into the aortopulmonary shunt during diastole. Children with this anatomy probably benefit from an right ventricular-pulmonary artery conduit.

In contrast to previous reports by Tweddell, ${ }^{3}$ McGuirk, ${ }^{13}$ and their associates, we could not identify a birth weight less than $2.5 \mathrm{~kg}$ as a risk factor for early death after the Norwood operation.

\section{Impact of Complications on Outcome}

Postoperative complications were common in our cohort although comparable with other contemporary reports. ${ }^{20}$ Patients who required cardiopulmonary resuscitation had significantly smaller diameters of the ascending aorta, indicating that myocardial ischemia and impaired ventricular dysfunction led to this complication. Cerebral complications decreased significantly with the avoidance of DHCA, which might improve neurodevelopmental outcome..$^{21,22}$

\section{Reduction of Interstage Mortality}

Interstage mortality between the Norwood and subsequent hemi-Fontan operation was $15 \%$ and comparable with previous reports from other centers. ${ }^{3,6,23}$ Again, the anatomy of MS/AA was a risk factor for death in the interim between the two operations, and we presume a similar pathophysiology for this. Additionally, cardiopulmonary resuscitation required during the hospital stay after the Norwood operation was also a risk factor for interstage death. An unbalanced relationship between the pulmonary and systemic circulations with subsequent myocardial ischemia and right ventricular dysfunction are potential mechanisms leading to hemodynamic instability and finally death. Fortunately, since the introduction of a home surveillance program in October 2005, interstage mortality has decreased significantly. As part of the program, all parents received strict guidelines to contact 
TABLE 4. Univariate risk factor analysis for 30-day and interstage mortality

\begin{tabular}{|c|c|c|}
\hline Risk factor & $\begin{array}{c}\text { Thirty-day mortality }(\mathbf{n}=157) \\
\text { OR }(95 \% \text { CI })\end{array}$ & $\begin{array}{c}\text { Interstage mortality }(\mathbf{n}=\mathbf{1 3 5}) \\
\text { OR }(95 \% \mathbf{C I})\end{array}$ \\
\hline Absent prenatal diagnosis & $1.38(0.51-3.77)$ & $1.14(0.40-3.27)$ \\
\hline Gender (female vs male) & $2.61(0.97-7.06)$ & $0.93(0.30-2.87)$ \\
\hline Premature infant & $0.85(0.10-7.13)$ & $1.07(0.12-9.28)$ \\
\hline MA/AA & $0.59(0.21-1.65)$ & $0.14(0.03-0.65)$ \\
\hline MS/AS & $0.76(0.24-2.45)$ & $1.24(0.40-3.83)$ \\
\hline MS/AA & $2.64(0.94-7.44)$ & $4.09(1.36-12.35)$ \\
\hline MA/AS & $0.76(0.09-6.30)$ & $1.98(0.38-10.28)$ \\
\hline Diameter ascending aorta $\leq 2 \mathrm{~mm}$ & $2.16(0.70-6.70)$ & $2.00(0.58-6.93)$ \\
\hline Tricuspid insufficiency & $1.12(0.23-5.37)$ & $0.54(0.07-4.46)$ \\
\hline Restrictive atrial septum & $0.96(0.11-8.18)$ & $1.26(0.14-11.16)$ \\
\hline Aberrant right subclavian artery & $4.13(1.12-15.15)$ & $2.29(0.43-12.10)$ \\
\hline Preoperative complications & $0.87(0.23-3.22)$ & $0.96(0.25-3.66)$ \\
\hline Preoperative inotropic support & $0.96(0.26-3.57)$ & $0.29(0.04-2.34)$ \\
\hline Preoperative ventilation & $1.02(0.34-3.06)$ & $0.34(0.07-1.59)$ \\
\hline Weight at operation $\leq 2.5 \mathrm{~kg}$ & $0.90(0.19-4.25)$ & $1.73(0.44-6.84)$ \\
\hline DHCA vs ASCP & $3.63(1.33-9.96)$ & $1.71(0.54-5.37)$ \\
\hline Duration of CPB (per 15-minute increase) & $1.03(0.87-1.22)$ & $0.94(0.78-1.14)$ \\
\hline Duration of ACC (per 15-minute increase) & $0.79(0.58-1.07)$ & $0.83(0.60-1.17)$ \\
\hline Duration of DHCA (per 15-minute increase) & $1.37(1.11-1.69)$ & $0.32(0.88-1.46)$ \\
\hline Duration of CIT (per 15-minute increase) & $1.87(1.23-2.85)$ & $1.06(0.67-1.68)$ \\
\hline Duration of TSPT (per 15-minute increase) & $1.36(1.12-1.65)$ & $1.01(0.77-1.34)$ \\
\hline Postoperative cardiopulmonary resuscitation & NA & $2.93(0.90-9.53)$ \\
\hline Postoperative hypoxemia, rhythm complications & NA & $0.74(0.22-2.44)$ \\
\hline Postoperative cerebral complications & NA & $0.81(0.10-6.89)$ \\
\hline Other postoperative complications & NA & $1.75(0.51-6.02)$ \\
\hline
\end{tabular}

OR, Odds ratio; $C I$, confidence interval; $M A / A A$, mitral atresia/aortic atresia; $M S / A S$, mitral stenosis/aortic stenosis; $M S / A A$, mitral stenosis/aortic atresia; $M A / A S$, mitral atresia/ aortic stenosis; $D H C A$, deep hypothermic circulatory arrest; $A S C P$, antegrade selective cerebral perfusion; $C P B$, cardiopulmonary bypass; $A C C$, aortic crossclamp; $C I T$, cardiac ischemic time; TSPT, total support time; $N A$, not applicable.

the hospital in case of failure to thrive or a decline in oxygen saturation and were contacted on a weekly basis. We are confident that this program is sufficient to detect any imbalance between pulmonary and systemic perfusion so that hospital admission and treatment can be initiated in time.

\section{Improvement of Actuarial Survival}

Jonas and colleagues ${ }^{16}$ reported on the early experience with the Norwood operation from the Boston group. They described the best long-term survival for patients with HLHS in the subgroup with MS/AS and the worst in the subgroup with MA/AA. This is in contrast to our findings, in which 1-year and 5-year survivals were superior in the subgroup of patients with MA/AA. However, Jonas and coworkers $^{16}$ reported on an early era of the Norwood operation, and treatment strategies, especially the technique of aortic arch reconstruction and anastomosis of the native hypoplastic ascending aorta with the neoaorta, have been modified since.

Improvements in this crucial part of the Norwood operation may well have reduced the risk for coronary stenosis and subsequent myocardial ischemia, especially in patients with a small ascending aorta universally present in the MA/AA subgroup. Indeed, Bartram, Grunenfelder, and
Van Praagh ${ }^{24}$ reported an analysis of postmortem cases of the early Boston series of HLHS patients and found that a stenosis at the site of the anastomosis of the native hypoplastic ascending aorta with the neoaorta was the most common cause of death at that time.

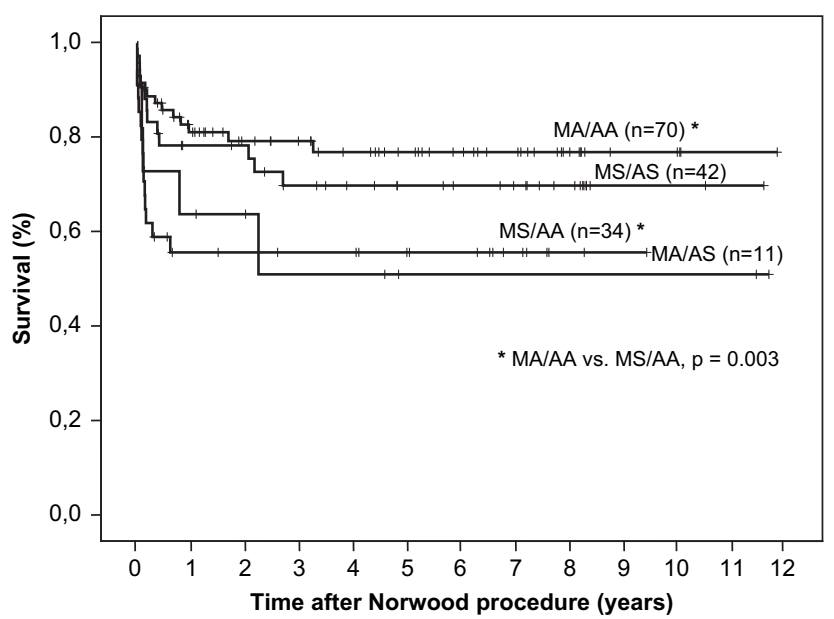

FIGURE 2. Kaplan-Meier actuarial survival curves between anatomic subgroups. $M A / A A$, Mitral atresia/aortic atresia; $M S / A S$, mitral stenosis/aortic stenosis; $M S / A A$, mitral stenosis/aortic atresia; $M A / A S$, mitral atresia/aortic stenosis. 
TABLE 5. Factor influencing long-term survival after successful Norwood operation (multivariate Cox regression analysis)

\begin{tabular}{lccr}
\hline \multicolumn{1}{c}{ Factor } & Hazard ratio & \multicolumn{1}{c}{$\mathbf{9 5} \% \mathbf{C I}$} & $\boldsymbol{P}$ value \\
\hline MS/AS vs MA/AA & 2.939 & $0.961-8.991$ & .059 \\
MS/AA vs MA/AA & 4.176 & $1.489-11.715$ & .012 \\
MA/AS vs MA/AA & 14.661 & $3.550-60.548$ & $<.001$ \\
Diameter ascending & 3.664 & $1.327-10.008$ & .012 \\
$\quad$ aorta $\leq 2$ mm & & & \\
$\begin{array}{l}\text { Postoperative cardiopulmonary } \\
\quad \text { resuscitation }\end{array}$ & 8.089 & $2.295-28.514$ & .001 \\
\end{tabular}

$\overline{C I \text {, Confidence interval; } M S / A S \text {, mitral stenosis/aortic stenosis; } M A / A A \text {, mitral atresia/ }}$ aortic atresia; $M S / A A$, mitral stenosis/aortic atresia; $M A / A S$, mitral atresia/aortic stenosis.

The restriction of shunt size to avoid pulmonary overcirculation might also have contributed to improved long-term survival. We used smaller modified Blalock-Taussig shunts than some other groups, although this will probably affect the timing of the second stage procedure. ${ }^{3}$

\section{Limitations of the Study}

Although data were collected prospectively, our patients were not randomly allocated to different therapeutic groups. A clear definition of distinct risk factors for 30-day, interstage, and long-term mortality is therefore hampered. Unfortunately, we cannot report on any postmortem data and therefore the cause of death, especially in the interstage period, remains unclear. Quantitative data on ventricular function are also lacking in our study but are clearly warranted to delineate the impact of the remnants of the left ventricle on right ventricular performance.

\section{CONCLUSION}

Thirty-day and interstage mortality after the Norwood operation for HLHS could remarkably be reduced in our series over a period of 12 years. The overall gain of experience, the introduction of standardized perioperative treatment protocols, and the initiation of a home surveillance program contributed to this improvement. However, patients with an anatomy of MS/AA still constitute the most challenging subgroup of HLHS with the lowest longer term survival.

We dedicate this work to Prof. Paul H. Heintzen (1925-2009), the founder and first director of the Department of Paediatric Cardiology, University-Hospital of Schleswig-Holstein, Campus Kiel, Kiel, Germany.

\section{References}

1. Gutgesell HP, Massaro TA. Management of hypoplastic left heart syndrome in a consortium of university hospitals. Am J Cardiol. 1995;76:809-11.

2. Meliones JN, Snider AR, Bove EL, Rosenthal A, Rosen DA. Longitudinal results after first-stage palliation for hypoplastic left heart syndrome. Circulation. 1990; 82(5 Suppl):IV151-6.

3. Tweddell JS, Hoffman GM, Mussatto KA, Fedderly RT, Berger S, Jaquiss RD, et al. Improved survival of patients undergoing palliation of hypoplastic left heart syndrome: lessons learned from 115 consecutive patients. Circulation. 2002; 106(12 Suppl 1):I82-9.
4. Mahle WT, Spray TL, Wernovsky G, Gaynor JW, Clark BJ 3rd. Survival after reconstructive surgery for hypoplastic left heart syndrome: a 15-year experience from a single institution. Circulation. 2000;102(19 Suppl 3): III136-41.

5. McGuirk SP, Griselli M, Stumper OF, Rumball EM, Miller P, Dhillon R, et al. Staged surgical management of hypoplastic left heart syndrome: a single institution 12 year experience. Heart. 2006;92:364-70.

6. Nilsson B, Mellander M, Sudow G, Berggren H. Results of staged palliation for hypoplastic left heart syndrome: a complete population-based series. Acta Paediatr. 2006;95:1594-600.

7. Tchervenkov CI, Jacobs JP, Weinberg PM, Aiello VD, Bélund MJ, Colan SD, et al. The nomenclature definition and classification of hypoplastic left heart syndrome. Cardiol Young. 2006;16:339-68.

8. Jacobs JP, O'Brien SM, Chai PJ, Morell VO, Lindberg HL, Quintessenza JA. Management of 239 patients with hypoplastic left heart syndrome and related malformation from 1993-2007. Ann Thorac Surg. 2008;85:1691-7.

9. Stieh J, Fischer G, Scheewe J, Uebing A, Dutschke P, Jung O, et al. Impact of preoperative treatment strategies on the early perioperative outcome in neonates with hypoplastic left heart syndrome. J Thorac Cardiovasc Surg. 2006;131:1122-9; e2.

10. Ghanayem NS, Hoffman GM, Mussatto KA, Cava JR, Frommelt PC, Rudd NA et al. Home surveillance program prevents interstage mortality after the Norwood procedure. J Thorac Cardiovasc Surg. 2003;126:1367-77.

11. Goldstein B, Giroir B, Randolph A. International pediatric sepsis consensus conference: definitions for sepsis and organ dysfunction in pediatrics. Pediatr Crit Care Med. 2005;6:2-8.

12. de Leval MR, Francois K, Bull C, Brawn W, Spiegelhalter D. Analysis of a cluster of surgical failures: application to a series of neonatal arterial switch operations. $J$ Thorac Cardiovasc Surg. 1994;107:914-23; discussion 23-24.

13. McGuirk SP, Stickley J, Griselli M, Stumper OF, Laker SJ, Barron DJ, et al. Risk assessment and early outcome following the Norwood procedure for hypoplastic left heart syndrome. Eur J Cardiothorac Surg. 2006;29:675-81.

14. Ishino K, Stumper O, De Giovanni JJ, Silove ED, Wright JG, Sethia B, et al. The modified Norwood procedure for hypoplastic left heart syndrome: early to intermediate results of 120 patients with particular reference to aortic arch repair. $J$ Thorac Cardiovasc Surg. 1999;117:920-30.

15. Gaynor JW, Mahle WT, Cohen MI, Ittenbach RF, DeCampli WM, Steven JM, et al. Risk factors for mortality after the Norwood procedure. Eur J Cardiothorac Surg. 2002;22:82-9.

16. Jonas RA, Hansen DD, Cook N, Wessel D. Anatomic subtype and survival after reconstructive operation for hypoplastic left heart syndrome. J Thorac Cardiovasc Surg. 1994;107:1121-7; discussion 7-8.

17. Vida VL, Bacha EA, Larrazabal A, Gauvreau K, Dorfman AL, Marx G, et al. Surgical outcome for patients with the mitral stenosis-aortic atresia variant of hypoplastic left heart syndrome. J Thorac Cardiovasc Surg. 2008;135:339-46.

18. Glatz JA, Tabbutt S, Gaynor JW, Rome JJ, Montenegro L, Spray TL, et al. Hypoplastic left heart syndrome with atrial level restriction in the era of prenatal diagnosis. Ann Thorac Surg. 2007;84:1633-8.

19. Sugiyama H, Yutani C, Iida K, Arakaki Y, Yamada O, Kamiya T. The relation between right ventricular function and left ventricular morphology in hypoplastic left heart syndrome: angiographic and pathological studies. Pediatr Cardiol. 1999;20:422-7.

20. Tweddell JS, Ghanayem NS, Mussatto KA, Mitchell ME, Lamers LJ, Musa NL, et al. Mixed venous oxygen saturation monitoring after stage 1 palliation for hypoplastic left heart syndrome. Ann Thorac Surg. 2007;84:1301-10; discussion 10-11.

21. Goldberg CS, Schwartz EM, Brunberg JA, Mosca RS, Bove EL, Schork MA, et al. Neurodevelopmental outcome of patients after the Fontan operation: a comparison between children with hypoplastic left heart syndrome and other functional single ventricle lesions. J Pediatr. 2000;137:646-52.

22. Mahle WT, Clancy RR, Moss EM, Gerdes M, Jobes DR, Wernovsky G. Neurodevelopmental outcome and lifestyle assessment in school-aged and adolescent children with hypoplastic left heart syndrome. Pediatrics. 2000;105: 1082-9.

23. Azakie T, Merklinger SL, McCrindle BW, Van Arsdell GS, Lee KJ, Benson LN, et al. Evolving strategies and improving outcomes of the modified Norwood procedure: a 10-year single-institution experience. Ann Thorac Surg. 2001;72: 1349-53.

24. Bartram U, Grunenfelder J, Van Praagh R. Causes of death after the modified Norwood procedure: a study of 122 postmortem cases. Ann Thorac Surg. 1997;64: 1795-802. 